Article

\title{
Designing Magnetic Layered Double Hydroxides and Two-Dimensional Magnetic Nano-Nets of Cobalt Ferrite through a Novel Approach
}

\author{
Osama Saber ${ }^{1,2, * \mathbb{C}}$, Abdullah Aljaafari ${ }^{1}{ }^{\mathbb{C}}$, Sarah Asiri ${ }^{3}$ and Khalid M. Batoo ${ }^{4}$ \\ 1 Physics Department, Faculty of Science, King Faisal University, Al-Hassa 31982, P.O. Box 400, \\ Hofuf 36291, Saudi Arabia; aaljaafari@kfu.edu.sa \\ 2 Egyptian Petroleum Research Institute, Nasr City, P.O. Box 11727, Cairo 11765, Egypt \\ 3 Biophysics Department, Institute for Research and Medical Consultations, \\ Imam Abdulrahman Bin Faisal University (IAU), Dammam 34212, Saudi Arabia; smasiri@iau.edu.sa \\ 4 King Abdullah Institute for Nanotechnology, King Saud University, P.O. Box 2455, \\ Riyadh 11451, Saudi Arabia; kbatoo@ksu.edu.sa \\ * Correspondence: osmohamed@kfu.edu.sa; Tel.: +966-13-589-9440
}

Received: 30 September 2018; Accepted: 25 October 2018; Published: 1 November 2018

\begin{abstract}
The present study has a dual aim of supporting magnetic nanoparticles over the nanolayers of LDHs and designing two-dimensional magnetic nano-nets of cobalt ferrite. In this trend, nanoparticles of $\mathrm{CoFe}_{2} \mathrm{O}_{4}$ were prepared and supported by $\mathrm{Co}-\mathrm{Fe} \mathrm{LDH}$ through urea hydrolysis. The nanolayered structures of Co-Fe LDH were confirmed by X-ray diffraction, energy-dispersive X-ray spectrometry, FT-IR spectra, thermal analyses, and transmission electron microscopy. In addition, they indicated that $13.2 \% \mathrm{CoFe}_{2} \mathrm{O}_{4}$ were supported over $\mathrm{Co}-\mathrm{Fe} \mathrm{LDH}$. Transformation of the nanolayered structures of $\mathrm{Co}-\mathrm{Fe} \mathrm{LDH}$ to nano-nets was achieved by the catalytic effect of the supported $\mathrm{CoFe}_{2} \mathrm{O}_{4}$ nanoparticles through solvent thermal technique. X-ray diffraction patterns and transmission electron microscopy images confirmed the transformation of the supported Co-Fe LDH to nano-nets of cobalt ferrite. In order to indicate the effect of the LDH for designing the nano-nets, nanoparticles of cobalt ferrite were prepared by the same technique without LDH. The magnetic behavior of the nano-nets and the supported Co-Fe LDH were measured and compared with the nanoparticles through vibrating sample magnetometer technique. The magnetic parameters indicated that the prepared nano-nets have ferromagnetic behavior and high coercivity. However, the prepared nanoparticles revealed a superparamagnetic state and low coercivity. The experimental results concluded that the incorporation of nanoparticles with nanowires into nano-net structures has been found to be an efficient way to improve their magnetic properties and prevent their agglomerations. Finally, layered double hydroxides are an important source for constructing magnetic nanolayered structures and nano-nets.
\end{abstract}

Keywords: magnetic cobalt ferrite nano-nets; magnetic layered double hydroxides; cobalt ferrite nanoparticles; magnetic measurements; transmission electron microscopy

\section{Introduction}

Nanostructures offer many advantages that open horizons for a wide variety of applications. Development of zero-, one-, and two-dimensional nanostructures has been a very interesting field for research because of the unique and amazing properties of the nanomaterials [1-3]. Therefore, the nanoparticles and the nanofibers have unlimited uses in various fields [4-6].

The most known tough magnetic material with a moderate saturation magnetization and high coercivity is cobalt ferrite. Also, it has high chemical stability and good mechanical 
hardness [7]. According to these advantages, it is considered a favorable material for magnetic fluids, permanent magnets, high-density magnetic recording [8], photo-magnetic material $[9,10]$, catalysis, and for modifying thawing agents [11]. A nanoscale design of magnetic materials leads to very promising phenomena in materials science. In this trend, magnetic nanocrystals were prepared by different synthetic methods [12-14]. However, the magnetic nanomaterials have a strong affinity to aggregate and form larger sizes because of their magnetic properties. This behavior leads to restrictions for their further applications. Therefore, in order to avoid particle agglomeration and control of particle size, many authors prepared magnetic nanoparticles dispersing in polymer, inorganic, amorphous, and vitreous matrices $[15,16]$. Magnetic nanocomposites were also prepared and dispersed in silica matrix [17-20].

The incorporation of nanoparticles with nanowires into nano-net structures may be a good solution for preventing the agglomeration of magnetic nanoparticles. The challenge is to obtain technique for producing magnetic nano-nets structures. Nano-nets consist of nanoparticles interlinked through ultrathin nanowires or nanofibers. In this trend, two-dimensional nano-nets based on gelatin or nylon-6 were fabricated by using electrospinning technique [21,22]. Also, the possibility of deliberately constructing tangled graphs and nets is canvassed [23].

It is known that two-dimensional layered materials confine organic or inorganic species in only one dimension. Among layered materials, layered double hydroxides (LDHs) are a group of synthetic two-dimensional nanomaterials whose structures can be described as nanolayered ordered material, in which the layers are cationic in nature and thus capable of intercalation anions. In general, LDHs may be characterized by the general formula $\left[\mathrm{MII}_{1-\mathrm{x}} \mathrm{MIII}_{\mathrm{x}}(\mathrm{OH})_{2}\right]^{\mathrm{x}+}\left(\mathrm{A}^{\mathrm{n}-}\right)^{\mathrm{x} / \mathrm{n}} \cdot \mathrm{mH}_{2} \mathrm{O}$, where MII and MIII are di- and tri-valent metals, respectively; the value of $x$ is equivalent to the molar ratio of MII/(MII+MIII) and $\mathrm{A}^{\mathrm{n}-}$ is an anion [24-27].

In the present study, layered double hydroxides are used as a source for constructing magnetic nanolayered structures and nano-nets. Co-Fe layered double hydroxides were prepared and supported by cobalt ferrite nanoparticles. Also, the nano-nets composed of cobalt ferrite are formed through a controlled decomposition of the nanolayers of Co-Fe LDH. Hitherto, there are no reports about a technique for producing nano-nets from layered double hydroxides. However, in this study, we have used a special procedure to perform a limited decomposition for the prepared Co-Fe LDH. It depends on supporting cobalt ferrite nanoparticles on the Co-Fe LDH to act as a catalyst in presence of high pressure of methanol and ethanol. The magnetic parameters of the nano-nets and the supported LDH were examined and compared with the cobalt ferrite nanoparticles through vibrating sample magnetometer technique.

\section{Materials and Methods}

\subsection{Preparation of the Cobalt Ferrite-Supported LDH}

During the construction of Co-Fe LDH, cobalt ferrite nanoparticles were prepared and supported over LDH. The nanolayers of Co-Fe LDH were grown through urea hydrolysis which used as a precipitant and $\mathrm{pH}$-controller $[12,13]$. Typically, cobalt chloride $(0.05 \mathrm{~mol})$ reacted with iron chloride $(0.02 \mathrm{~mol})$ at $90^{\circ} \mathrm{C}$ in presence of 0.5 mole of urea. Decomposition reactions of urea were source for producing anions such as cyanate and carbonate. The mixture was heated for long time until $\mathrm{pH}$ was above seven. After several washes and filtrations, the product was dehydrated under vacuum at room temperature.

\subsection{Transformation of the Supported LDH to Nano-Nets}

A suitable quantity of the supported LDH was dispersed in $120 \mathrm{~mL}$ of methanol for $12 \mathrm{~h}$. Then, the mixture was retained with $500 \mathrm{~mL}$ ethanol in a pressurized container with a temperature controller unit (autoclave) as shown in Figure 1. A limited decomposition of the supported LDH was achieved under supercritical conditions (temperature $=250{ }^{\circ} \mathrm{C}$ and pressure $=100 \mathrm{bar}$ ). The temperature of 
the alcoholic solution in the autoclave was gradually increased to become higher than the critical temperature of the solvent. Accordingly, the pressure increased to reach a value higher than the critical value. At critical temperature and pressure, methanol and ethanol become gases and cannot be liquefied because of the supercritical fluids. After that, the pressure released from the autoclave approaches the atmospheric pressure. The inert gas (argon) was used to evacuate any remaining gases until the temperature of the autoclave reached to room temperature to prevent liquid condensation inside the pores of the prepared structure.

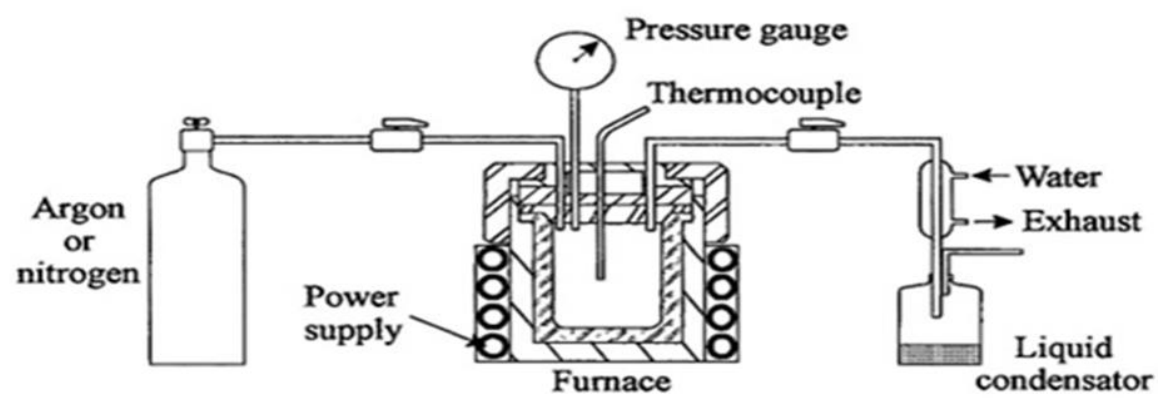

Figure 1. A pressurized vessel with a temperature controller unit [28].

\subsection{Preparation of Nanoparticles}

For comparison, the same technique was used for preparing cobalt ferrite without $\mathrm{LDH}$ structures. Cobalt chloride $(0.05 \mathrm{~mol})$ and iron chloride $(0.02 \mathrm{~mol})$ were dissolved in methanol for $12 \mathrm{~h}$. Ethanol was mixed with the solution and was placed in the pressurized vessel with a temperature controller unit. The reaction was carried out under supercritical conditions (temperature $=250{ }^{\circ} \mathrm{C}$ and pressure $=100$ bar). The product was collected in powder form.

\subsection{Physical Characterization}

Powder X-ray diffraction (XRD) spectra were registered between $4^{\circ}$ and $70^{\circ}$ on a Bruker-AXS, Germany using $\mathrm{CuK} \alpha$ (filtered) radiation $(\lambda=0.154 \mathrm{~nm})$ at $40 \mathrm{kV}$ and $30 \mathrm{~mA}$. Thermogravimetric analysis (TGA) carried out in TA instruments incorporated high-resolution thermogravimetric analyzer (series Q500) under N2 atmosphere to a maximum temperature of $800{ }^{\circ} \mathrm{C}$. Differential scanning calorimetry (DSC) analysis was carried out using TA series Q 600 (USA) under $\mathrm{N}_{2}$ atmosphere, with a heating rate of $10{ }^{\circ} \mathrm{C} \mathrm{min}^{-1}$. FT-IR spectra ( $\mathrm{KBr}$ disc method) were recorded on a Perkin Elmer Spectrum 400. Transmission electron microscopy (TEM) was carried out at room temperature using JEM 2100F with $200 \mathrm{kV}$ acceleration voltage. Energy-dispersive X-ray spectrometry (EDS) measurements were carried out with an Electron Probe Micro analyzer JED 2300. Magnetic measurements were performed at room temperature using microsense EV9 model vibrating sample magnetometer (VSM) with a maximum applied field of $\pm 2 \mathrm{~T}$.

\section{Results}

\subsection{Supporting Cobalt Ferrite Nanoparticles over Co-Fe LDH}

X-ray diffraction pattern of Co-Fe LDH is given in Figure 2. It exhibited the typical XRD pattern of the carbonate-form of $\mathrm{LDH}$, which reported in the literature. Symmetric reflections for the basal (003), (006), and (009) planes were observed in Figure 2 exhibiting sharp peaks. Also, Figure 2 showed asymmetric reflections for the non-basal (012), (015), and (018) planes at high two theta indicating that the product has the layered structure of hydrotalcite-like materials (JCPDS file no. 50-0235). The clear arrangement among the symmetric reflections of the basal planes, i.e., $d_{003}=2 \times d_{006}=3 \times d_{009}$ for $\mathrm{Co}-\mathrm{Fe} \mathrm{LDH}$, indicated that the Co-Fe layers are highly packed in ordered form along axis $\mathrm{c}$. The lattice parameter " $c$ " is estimated as $3 \times \mathrm{d}_{003}$ and is used to determine the thickness of the layer and the interlayer distance. From the XRD analysis, the position of the (110) reflection allowed calculation of 
the parameter ' $a$ ' $\left(a=2 \times d_{110}\right)$. The lattice parameter ' $a$ ' is used to determine the average distance between cobalt and iron cations inside the brucite-like layer. These lattice parameters were calculated: basal spacing, $\mathrm{d}_{003}=0.76 \mathrm{~nm}$; a-axis, $\mathrm{a}=0.31 \mathrm{~nm}$; and c-axis, $\mathrm{c}=2.28 \mathrm{~nm}$. These parameters were similar to that reported for the natural and synthetic hydrotalcite in the case of the guests are carbonate and/or cyanate [29]. In addition, weak peaks of cobalt ferrite $\mathrm{CoFe}_{2} \mathrm{O}_{4}$ (JCPDS file no. 79-1744) were observed. According to the XRD calculations, the percentage of $\mathrm{CoF}_{\mathrm{e} 2} \mathrm{O}_{4}$ was about $13.2 \%$. It means that some crystals of cobalt ferrite formed at low temperature and supported over the nanolayers of Co-Fe LDH.

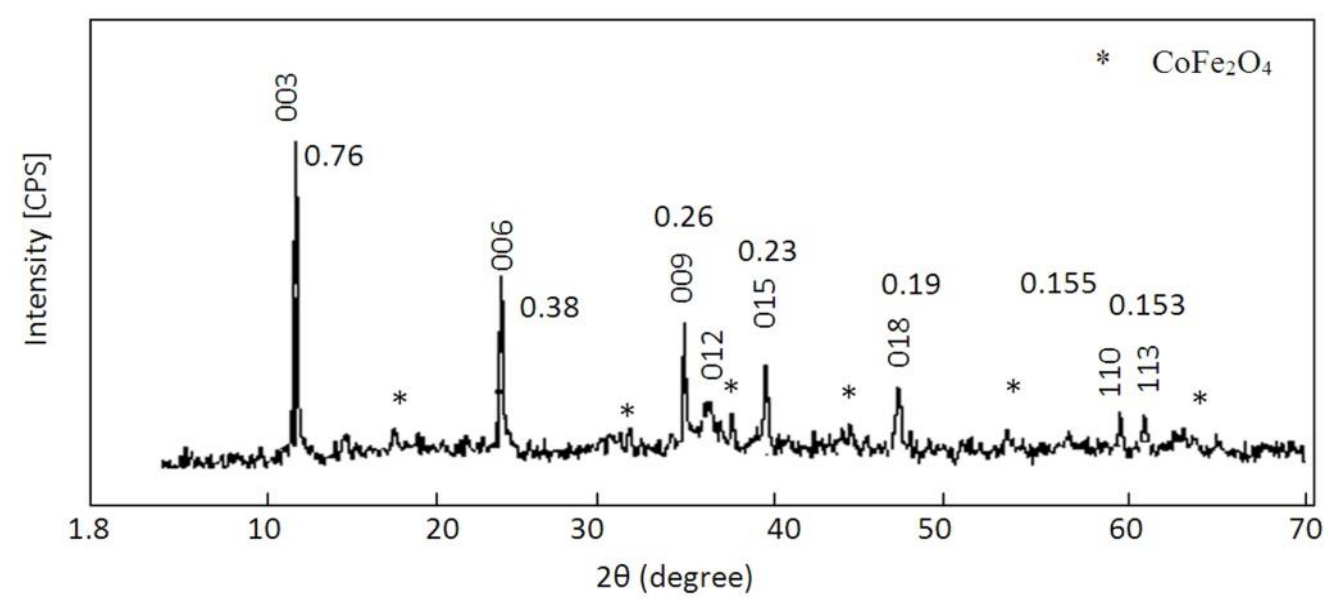

Figure 2. X-ray diffraction pattern of the $\mathrm{CoFe}_{2} \mathrm{O}_{4}$-supported $\mathrm{Co}-\mathrm{Fe} \mathrm{LDH}$.

The symmetry and the nature of the functional groups of Co-Fe LDH were identified through the FT-IR technique as shown in Figure 3. The vibration of the hydroxyl groups of LDH was observed at $3400 \mathrm{~cm}^{-1}$ as a broad absorption band. The broadness of the $\mathrm{OH}$ band was due to existence of hydrogen bonds which was confirmed by observing weak band at $2952 \mathrm{~cm}^{-1}$ for the $\mathrm{OH}$ stretching mode of the hydrogen bonds to the interlayered anions $[15,16]$. The insertion of cyanate anions into the Co-Fe LDH structure was verified by the appearance of the $v_{1}$ vibration at $2190 \mathrm{~cm}^{-1}$ [29].

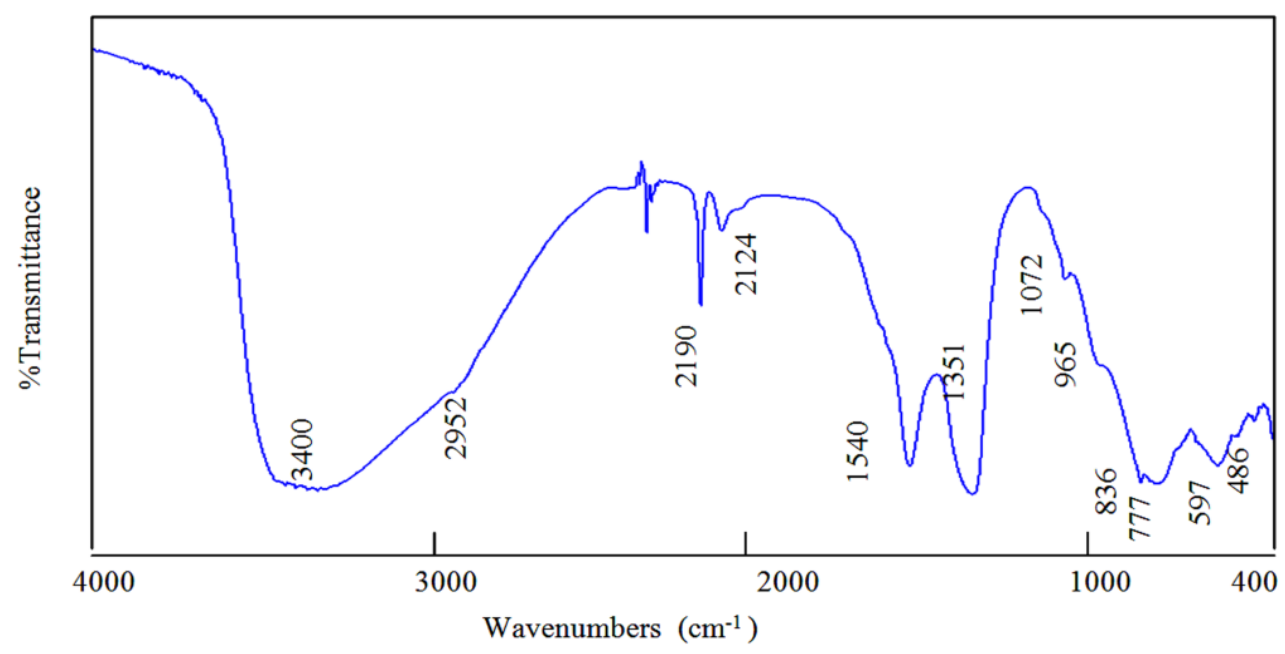

Figure 3. FT-IR spectrum of the $\mathrm{CoFe}_{2} \mathrm{O}_{4}$-supported Co-Fe LDH.

A close-up of the vibration region of cyanate anions showed that this band is actually split into two bands because of the lowering of the anion's symmetry. This splitting was clear in Figure 3 where, there is another peak at $2124 \mathrm{~cm}^{-1}$ accompanied with $2190 \mathrm{~cm}^{-1}$. Also, the presence of the interlayered carbonate anions was confirmed by observing two bands at $1540 \mathrm{~cm}^{-1}$ and $1351 \mathrm{~cm}^{-1}[17,18]$. This vibration mode $v_{3}$ is recorded at $1450 \mathrm{~cm}^{-1}$ for free carbonate species, but the 
symmetry lowering of the interlayered carbonate caused splitting and shifting for this band. In addition, the vibration mode $v_{1}$ of carbonate anion was observed at $1072 \mathrm{~cm}^{-1}$ [18]. The bands at $965 \mathrm{~cm}^{-1}$ and $836 \mathrm{~cm}^{-1}$ were attributed to the mode $v_{2}$ of carbonate anion while the mode $v_{4}$ of carbonate anion was clear at $777 \mathrm{~cm}^{-1}$. Two other bands, located at $597 \mathrm{~cm}^{-1}$ and $486 \mathrm{~cm}^{-1}$, could be attributed to the $\mathrm{Fe}-\mathrm{OH}$ and $\mathrm{Co}-\mathrm{OH}$ bending vibration; respectively [19]. These results indicated that the prepared Co-Fe LDH has a similar structure to the usual LDH structure.

Thermal characteristics of the supported LDH were determined by TG and DSC as shown in Figure 4. The TG diagram of Co-Fe LDH revealed four weight losses as shown in Figure 4a. The first and the second weight losses up to $160{ }^{\circ} \mathrm{C}$ was $10 \%$ representing release of both the surface and the intercalated water of the $\mathrm{LDH}$. The third weight loss was $7 \%$ and occurred from $161^{\circ} \mathrm{C}$ to $265^{\circ} \mathrm{C}$ because of the oxidation of the cyanate anions. The fourth weight loss happened from $272{ }^{\circ} \mathrm{C}$ to $417^{\circ} \mathrm{C}$. It was $8 \%$ corresponding to the decomposition of carbonate anions and the dehydroxylation process. DSC diagram confirmed the TG results. One endothermic peak was observed at $155^{\circ} \mathrm{C}$ indicating release of the water of the $\mathrm{LDH}$ structure as shown in Figure $4 \mathrm{~b}$. The second peak at $269^{\circ} \mathrm{C}$ was exothermic agreeing with the exothermic and endothermic effects of the oxidation of cyanate anions and the decomposition of carbonate anions. There is a small exothermic peak observed for the fourth weight loss, suggesting the occurrence of a reaction between the products of the oxidation of cyanate anions and the decomposition products of carbonate anions during the dehydroxylation process of the layers.

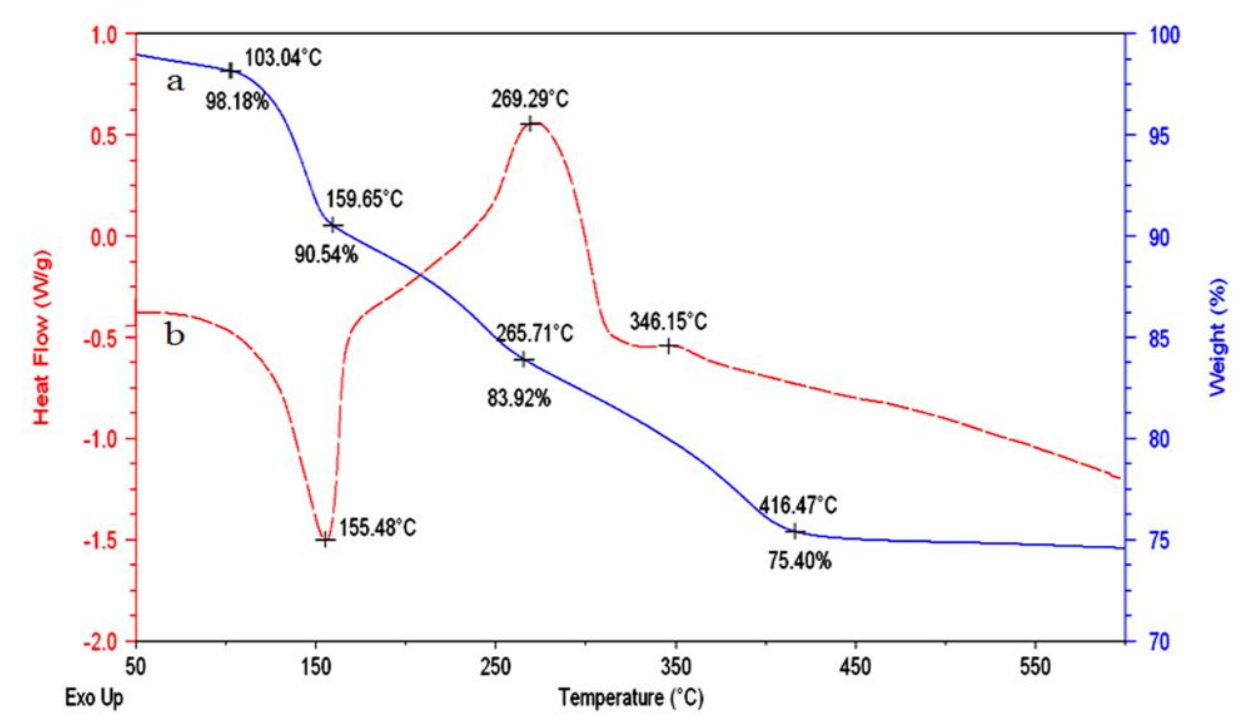

Figure 4. Thermal analyses (TG and DSC) of the $\mathrm{CoFe}_{2} \mathrm{O}_{4}$-supported Co-Fe LDH.

It is known that the crystals of the hydrotalcite-like compounds have hexagonal plate-like morphology if carefully crystallized [20]. A similar morphology was observed for the prepared Co-Fe LDH with ultra-thin plates as shown in Figure 5. The lateral view for the plates of LDH showed that the thickness of the plates was less than $20 \mathrm{~nm}$ as shown in Figure $5 \mathrm{~d}$. It means that the plates of the prepared Co-Fe LDH consist of less than 20 nanolayers. In addition, Figure $5 \mathrm{a}, \mathrm{b}$ showed agglomerations of some nanoparticles. At a high magnification, Figure $5 \mathrm{c}$, d showed that these particles have a nearly spherical shape and their size are in the range of $5 \mathrm{~nm}$. Agreeing with $X R D$ results, these nanoparticles are cobalt ferrite $\left(\mathrm{CoFe}_{2} \mathrm{O}_{4}\right)$ and their agglomerations are due to their magnetic properties. 

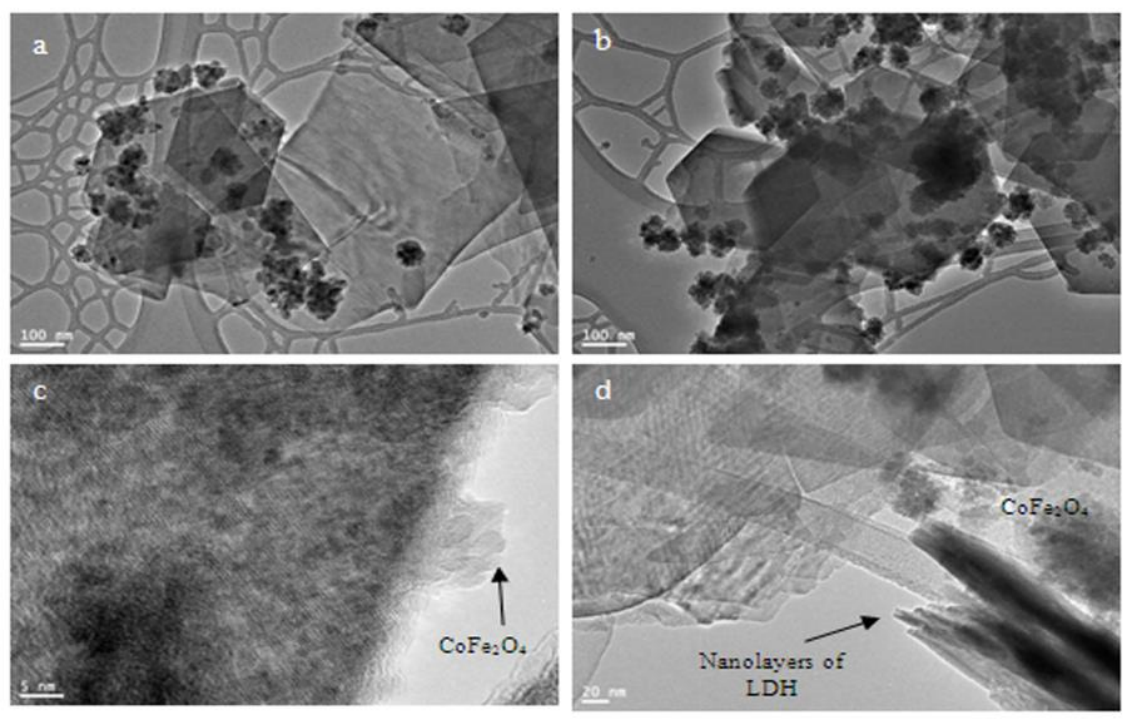

Figure 5. TEM images of the $\mathrm{CoFe}_{2} \mathrm{O}_{4}$-supported Co-Fe LDH.

The concentration of the different elements was obtained from EDX analysis for two locations in the platelets of the LDH. Figure 6 showed that cobalt, iron, and oxygen were clearly identified in the platelets of the Co-Fe LDH. By the comparison among the EDX diagrams of the two different spots, it showed that the different elements are homogeneously distributed in the sample. The SEM and EDX results indicated that $\mathrm{Co}-\mathrm{Fe} \mathrm{LDH}$ is prepared and supported by cobalt ferrite nanoparticles.
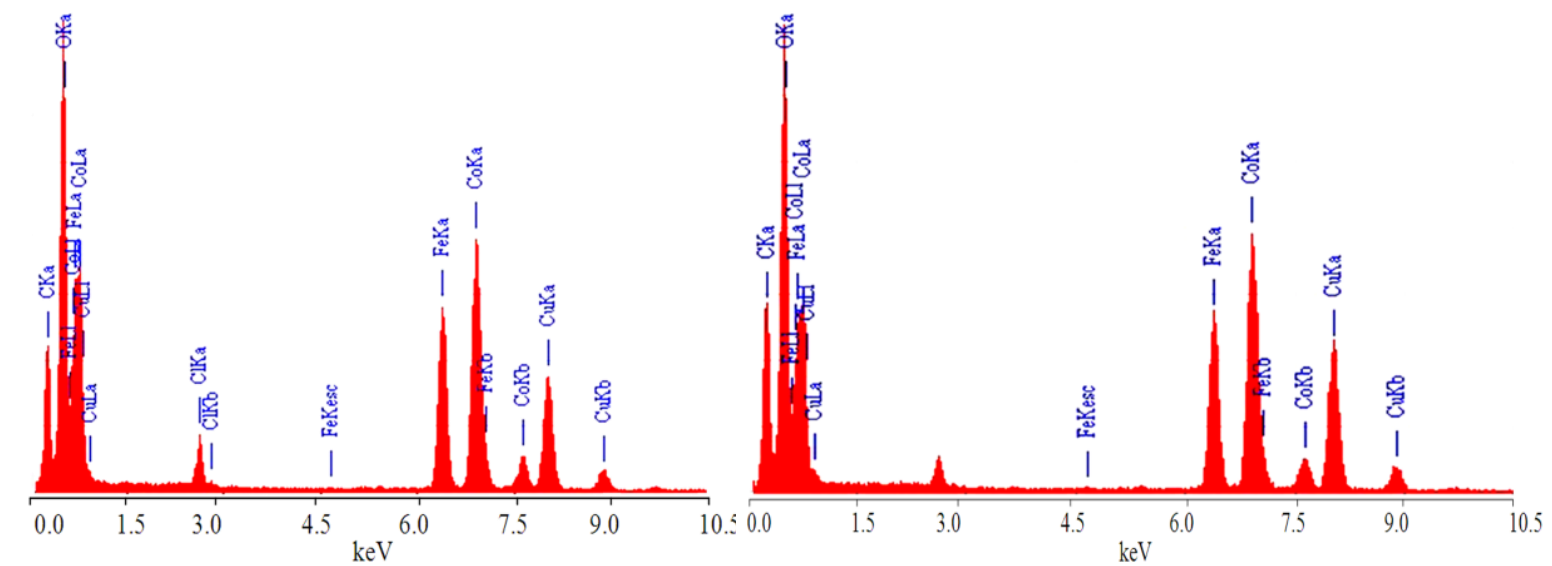

Figure 6. EDX spectra of the $\mathrm{CoFe}_{2} \mathrm{O}_{4}$-supported Co-Fe LDH.

\subsection{Transformation of the Nanolayers to the Nano-Nets}

Figure 7 illustrates the XRD pattern of the product obtained by the decomposition of the supported LDH under critical conditions of pressure and temperature in presence of methanol and ethanol. The XRD pattern exhibited the characteristic diffractions peaks of cobalt ferrite (JCPDS 79-1744). The main diffraction peaks of the planes (220), (311), (400), (511), and (440) of cobalt ferrite were broad suggesting that their crystals are in the nano scale. In the same time, the characteristic peaks of the lamellar structure of LDH disappeared. It means that the layered structure of Co-Fe LDH was transformed to a clear phase of cobalt ferrite. The crystallite size of the produced cobalt ferrite was calculated from the XRD line broadening using the following Scherer relationship [30].

$$
\mathrm{D}=\mathrm{k} \lambda / \beta \operatorname{Cos} \theta[\mathrm{k}=0.9, \lambda=0.15405 \mathrm{~nm}]
$$




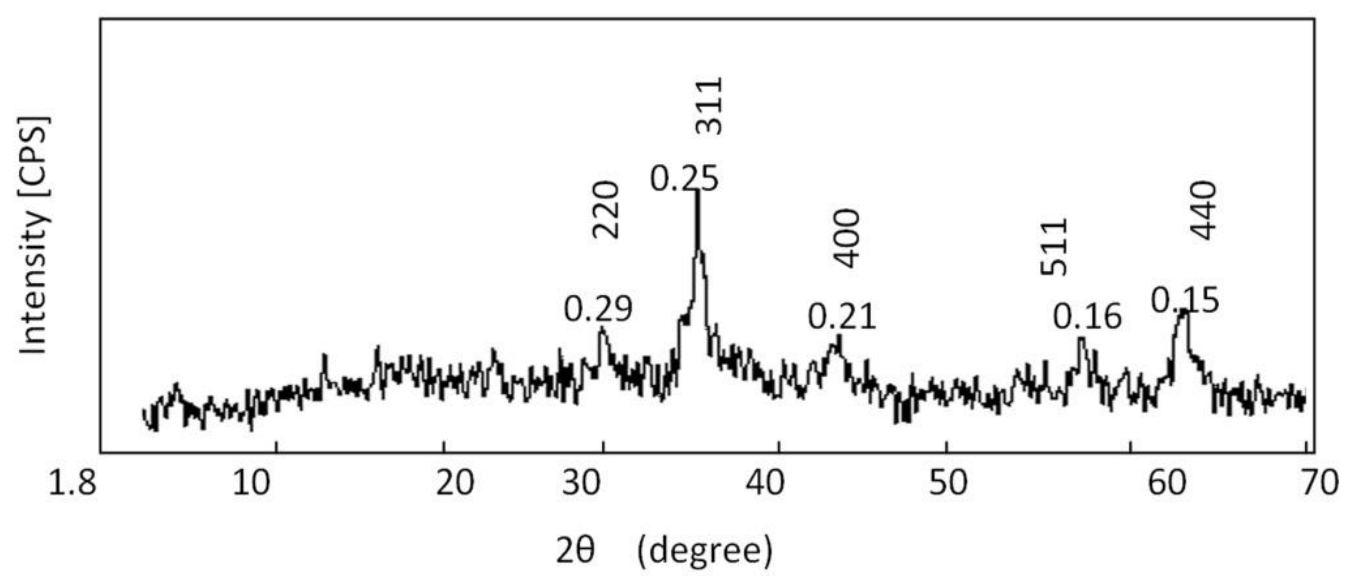

Figure 7. X-ray diffraction pattern of the $\mathrm{CoFe}_{2} \mathrm{O}_{4}$-supported Co-Fe LDH after thermal treatment.

According to Scherer equation, the particles crystallite sizes of cobalt ferrite are in the range of $7 \mathrm{~nm}$. The nanostructure of this product was confirmed by TEM. The TEM images in Figure 8 showed that the produced cobalt ferrite is composed of nano-nets. These nano-nets consist of nanoparticles and short nanowires as shown in Figure $8 \mathrm{c}, \mathrm{d}$. Also, Figure $8 \mathrm{c}, \mathrm{d}$ revealed that these nano-nets have nano-pores with diameters of $5-10 \mathrm{~nm}$.
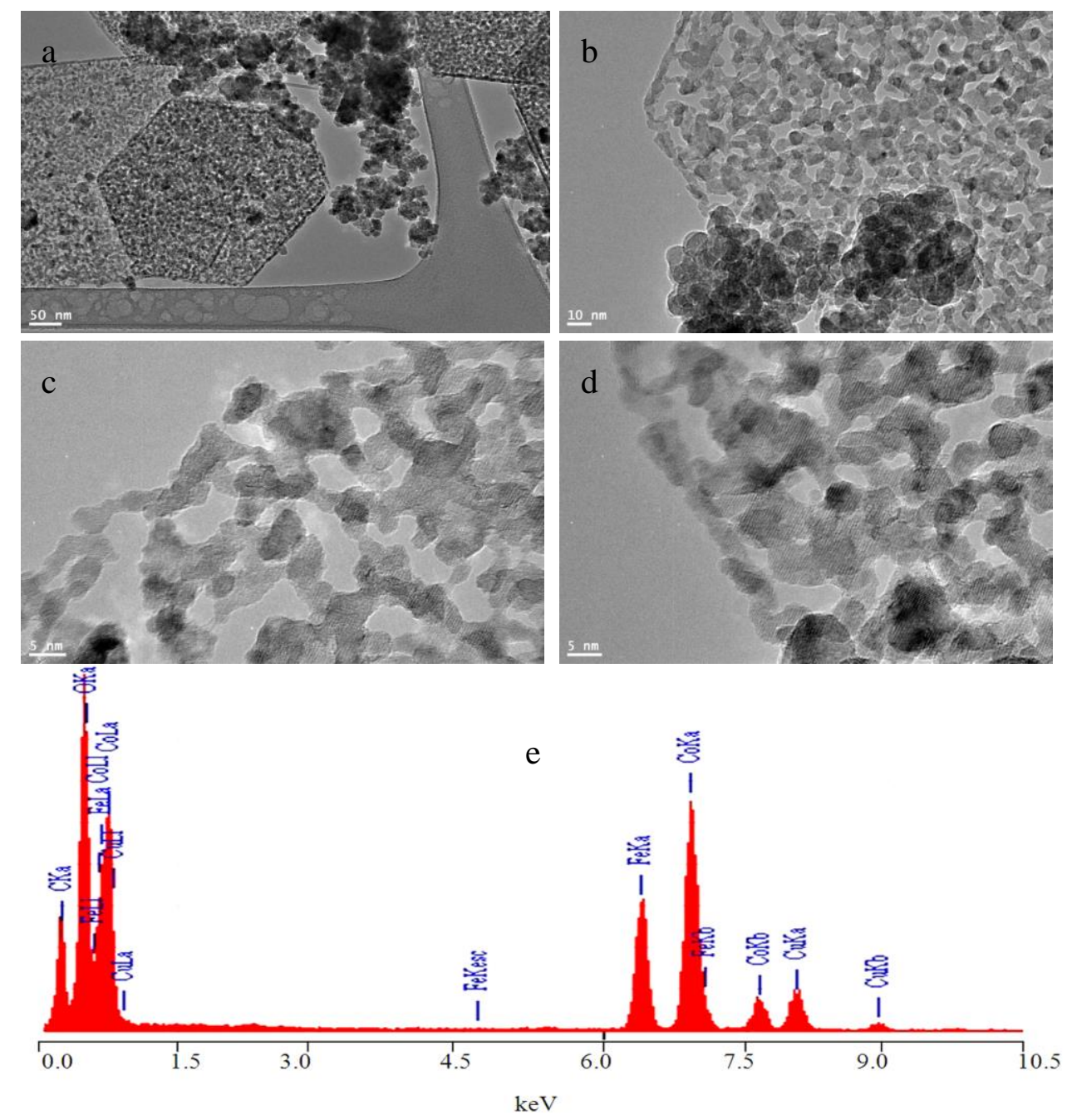

Figure 8. TEM images and EDX spectrum of the $\mathrm{CoFe}_{2} \mathrm{O}_{4}$ nano-nets. 
In addition, aggregations of the nanoparticles were observed in Figure $8 \mathrm{a}, \mathrm{b}$. These nanoparticles were also observed in the $\mathrm{Co}-\mathrm{Fe} \mathrm{LDH}$ before the thermal treatment and were due to $\mathrm{CoFe}_{2} \mathrm{O}_{4}$. These nanoparticles have spherical shape with size less than $10 \mathrm{~nm}$ as shown in Figure $8 \mathrm{~b}$. These nanoparticles did not change after the thermal treatment. This means that these nanoparticles act as catalysts during the decomposition reactions of LDH structures, where the catalyst does not change during the reaction. By using EDX technique, cobalt, iron, and oxygen were clearly identified in the nano-nets of cobalt ferrite as shown in Figure 8e. It is known that the signals of the copper and the carbon belong to the carbon-coated copper grid for the TEM testing.

\subsection{Mechanism of the Nano-Nets Formation}

Nanolayers are one of the most significant kinds of nanomaterials. New physical effects and a wide variety of functionalities can be achieved by nanoscale engineering of surfaces and layers. Here the assumption is that the LDHs have a single-layer material, the dimensions of the nanosheet can be up to a micrometer, while the thickness is only about one nanometer. As a result, LDHs exhibit plate-like shapes and contain nanolayers. The separation process for LDHs is known as exfoliation or delamination. The delamination of the layered structures is spontaneous because of the weak interactions between the nanolayers of the LDHs. The individual crystallites are called nanosheets and have remarkable chemical and physical properties because of their small thickness with respect to a bulk material. Inorganic nanosheets are possibly suitable as building blocks for advanced inorganic materials. Therefore, these nanosheets might be a very promising material for fabrication of nano-nets.

According to the structure of Co-Fe layered double hydroxides, they have a huge interlayered space and contain 15\% interlayered anions (carbonate and cyanate) in addition to $10 \%$ interlamellar water. Formation of nano-nets could be explained through the catalytic effect of the cobalt ferrite nanoparticles that was supported over LDH structures. The treatment of LDHs with methanol for a long time caused interaction between the hydroxyl groups of methanol and the nanolayers of LDHs. At critical conditions of temperature and pressure, the nanoparticles of cobalt ferrite acted as catalysts for driving and accelerating the decomposition reactions of methanol molecules as shown in the equation

$$
\mathrm{CH}_{3} \mathrm{OH} \rightarrow \mathrm{CO}+2 \mathrm{H}_{2}
$$

Many authors confirmed this catalytic reaction [31,32]. It means that each one mole of methanol produces three moles of hydrogen and carbon monoxide inside the solid material. By this way, large amount of gases was produced inside the LDH structures. Also, decomposition reactions of cyanate and carbonate anions increased the amount of gases among the layers. To release all these gases from the rigid nanolayers of LDHs, holes and vacancies were formed during the transformation of Co-Fe LDH to cobalt ferrite through the dehydroxylation process of the nanolayers. At the same time, the internal pressure of these gases inside the nanolayered structures directed the hexagonal plates of LDH to produce nano-net morphology.

In order to confirm this speculation, the same technique was used to prepare magnetic nano-nets without LDH. It failed to produce the nano-nets. It showed nanoparticles of cobalt ferrite as shown in Figure 9. These results concluded that layered double hydroxides are suitable materials for fabricating the nano-nets of cobalt ferrite. 

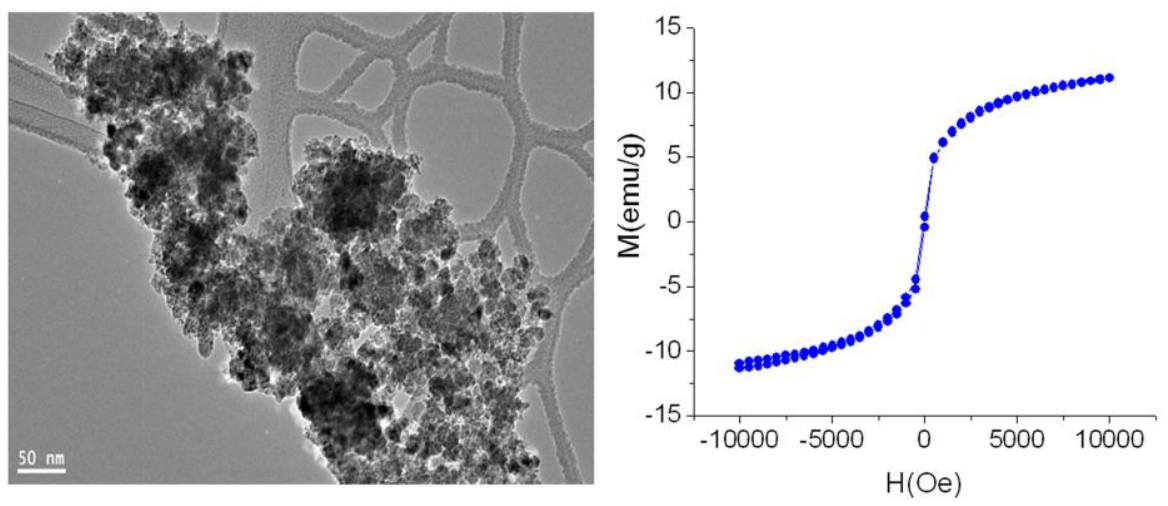

Figure 9. TEM images and magnetization $\mathrm{M}-\mathrm{H}$ curves of the $\mathrm{CoFe}_{2} \mathrm{O}_{4}$ nanoparticles.

\subsection{Magnetic Properties}

In order to study the magnetic behavior of the supported Co-Fe LDH and the cobalt ferrite nano-nets, the magnetization parameters were determined through the curves of magnetization against the magnetic field.

The magnetization $(\mathrm{M})$ was measured with the applied magnetic field $(\mathrm{H})$ between $-20 \mathrm{kOe}$ and $+20 \mathrm{kOe}$ at $300 \mathrm{~K}$ by VSM to build M-H curves. The saturation magnetization $\left(\mathrm{M}_{\mathrm{s}}\right)$, the remnant magnetization $\left(\mathrm{M}_{\mathrm{r}}\right)$ and the coercivity $\left(\mathrm{H}_{\mathrm{c}}\right)$ were summarized in Table 1 for the supported $\mathrm{LDH}$, the nano-nets and the prepared nanoparticles of cobalt ferrite.

Table 1. Magnetic data for the cobalt ferrite-supported LDH, cobalt ferrite nano-nets, and cobalt ferrite nanoparticles.

\begin{tabular}{|c|c|c|c|c|}
\hline Samples & $M_{s}\left(e m u g^{-1}\right)$ & $M_{r}\left(e g^{-1}\right)$ & $\mathrm{H}_{\mathrm{c}}(\mathrm{Oe})$ & $\mathrm{QS}\left(\mathrm{M}_{\mathrm{r}} / \mathrm{M}_{\mathrm{s}}\right)$ \\
\hline $\mathrm{CoFe}_{2} \mathrm{O}_{4} / \mathrm{Co}-\mathrm{Fe} \mathrm{LDH}$ & $10.69 \pm 0.05$ & $1.36 \pm 0.007$ & $2.60 \pm 0.01$ & 0.13 \\
\hline $\mathrm{CoFe}_{2} \mathrm{O}_{4}$ nano-nets & $6.44 \pm 0.03$ & $2.30 \pm 0.01$ & $1277 \pm 6$ & 0.36 \\
\hline $\mathrm{CoFe}_{2} \mathrm{O}_{4}$ nanoparticles & $11 \pm 0.05$ & $0.25 \pm 0.001$ & $35 \pm 0.2$ & 0.023 \\
\hline
\end{tabular}

By increasing the external magnetic field of strength $(\mathrm{H})$, the $\mathrm{M}-\mathrm{H}$ curve of the supported Co-Fe LDH indicated that the magnetization (M) increased reaching to saturation value at $10.69 \mathrm{emu} \mathrm{g}^{-1}$ as shown in Figure 10a. Also, Figure 10a exhibited a hysteresis loop including two branches for the magnetization and demagnetization processes. This means that the supported Co-Fe LDH has ferromagnetic behavior.

The amount of the reverse field for demagnetizing the ferromagnetic material to zero is coercivity $\left(\mathrm{H}_{\mathrm{c}}=2.6 \mathrm{Oe}\right)$. The remnant magnetization $\left(\mathrm{M}_{\mathrm{r}}\right)$ was $1.36 \mathrm{emu} \mathrm{g}^{-1}$ when the external magnetic field returned to zero. This indicated that all domains of the supported Co-Fe LDH did not return to their original orientation when the external magnetic field decreased to zero.

In the case of the cobalt ferrite nano-nets, it showed and S-type curve with a wide hysteresis loop, representing the behavior of ferromagnetism as shown in Figure 10b. The saturation magnetization $\left(\mathrm{M}_{\mathrm{s}}\right)$ and remenant magnetization $\left(\mathrm{M}_{\mathrm{r}}\right)$ of the nano-nets were $6.44 \mathrm{emu}^{-1}$ and $2.3 \mathrm{emu} \mathrm{g}^{-1}$; respectively. The coercitivity $\left(\mathrm{H}_{\mathrm{c}}\right)$ of the nano-nets has been found at $1277 \mathrm{Oe}$. The prepared nanoparticles of cobalt ferrite revealed S-type curve with no hysteresis loop as shown in Figure 9. This is a typical behavior of superparamagnetism. By comparing with the prepared nanoparticles of cobalt ferrite, both the supported LDH and the nano-nets showed ferromagnetic behavior. However, the supported LDH and the nano-nets are composed of nanoparticles. It means that the morphology of the nanoparticles has an important role for controlling their magnetic properties. The low value of saturation magnetization of the nano-nets compared to the supported LDH and the nanoparticles could be explained in the light of morphology of the sample. Where, the nano-nets are composed of nanoparticles and nanowires 
in addition to vacancies and holes. The presence of vacancies and interatomic spacing caused low magnetization in the nano-nets of the ferrite $[33,34]$.

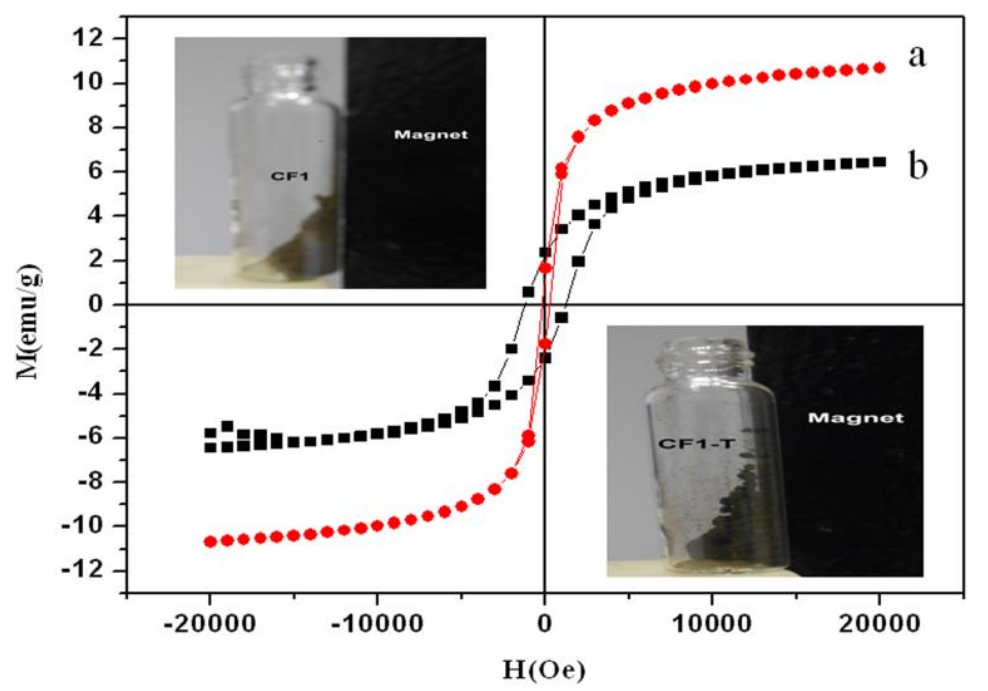

Figure 10. Magnetization $\mathrm{M}-\mathrm{H}$ curves of: (a) the $\mathrm{CoFe}_{2} \mathrm{O}_{4}$-supported $\mathrm{LDH}$ and (b) the $\mathrm{CoFe}_{2} \mathrm{O}_{4}$ nano-nets.

On the other side, the nano-nets have a coercive field value (1277 Oe) that is higher than the prepared nanoparticles of cobalt ferrite ( 35 Oe) and the bulk ferrite ( 980 Oe) [35]. The previous work [36] concluded that the morphology of the crystals has effect on the coercivity in this order: octahedral $>$ cubes $>$ spheres in line with the rise in the number of magnetic axes along this arrangement of forms. In the same direction, the coercivity of the nano-nets was higher than that of the prepared nanoparticles because of the number of axes and the high aspect ratio of the nano-nets.

The squareness ratio SQ represents the easiness with which the magnetization re-orients to the nearest axis magnetization after the removal of the magnetic field. The squareness ratio is calculated by the ratio of remnant magnetization to saturation magnetization $\left(S Q=M_{r} / M_{S}\right)$ [37]. It indicates the exchange interactions and magneto-crystalline anisotropy accompanying the nanoparticles [38]. A theoretical SQ value of the uniaxial anisotropy of single domain magnetic nanoparticles is 0.5 , while an SQ value of 0.83 indicates the existence cubic magneto-crystalline anisotropy for bulk ferrite [39]. In the prepared nano-nets, SQ was 0.36 (close to 0.5) which means that it has uniaxial anisotropy of single domain magnetic nanoparticles because the nano-nets consist of nanoparticles and nanowires.

\section{Discussion}

The present study has a dual aim for supporting magnetic nanoparticles over the nanolayers of layered double hydroxides and designing magnetic nano-nets of cobalt ferrite, which is not yet published in the literature.

The first aim was achieved through precipitating nanoparticles of cobalt ferrite during construction of the nanolayered structures of the LDH. According to the reaction mechanism of urea hydrolysis [29], it decomposes through two steps to produce cyanate and/or carbonate anions in addition to ammonium cation as shown in the following reactions:

$$
\begin{gathered}
\text { Urea }+\mathrm{H}_{2} \mathrm{O} \rightarrow \mathrm{NH}_{4}^{+}+\mathrm{OH}^{-}+\mathrm{CNO}^{-}+\mathrm{H}^{+} \\
\mathrm{CNO}^{-}+2 \mathrm{H}_{2} \mathrm{O} \rightarrow \mathrm{NH}_{4}^{+}+\mathrm{CO}_{3}{ }^{2-}
\end{gathered}
$$

The acidic medium of the solution gradually changes to become alkaline. At these conditions, the layered structures of Co-Fe LDH starts to grow. During the hydrolysis of urea, the iron cations $\mathrm{Fe}^{3+}$ 
react with $\mathrm{OH}^{-}$ions generating goethite $\mathrm{Fe}(\mathrm{OOH})$. In addition, cobalt hydroxide is formed by reacting the cobalt cations $\mathrm{Co}^{2+}$ with $\mathrm{OH}^{-}$ions [40].

$$
2 \mathrm{Fe}(\mathrm{OOH})+\mathrm{Co}(\mathrm{OH})_{2} \rightarrow \mathrm{CoFe}_{2} \mathrm{O}_{4}+2 \mathrm{H}_{2} \mathrm{O}
$$

According to Equation (5), nanoparticles of cobalt ferrite can be synthesized during the building of LDH. Agreeing with XRD results, 13.2\% nanoparticles of cobalt ferrite has been prepared and supported by the nanolayered structures of Co-Fe LDH.

The second aim was accomplished by treating the supported LDH at critical pressure and temperature. By critical conditions of temperature and pressure, the supported LDH was transformed into nano-nets of cobalt ferrite. These nano-nets consist of nanoparticles and short nanowires. TEM images revealed that the nano-nets have nano-pores with diameters of 5-10 nm. Formation of the cobalt ferrite nano-nets could be explained through the catalytic effect of the cobalt ferrite nanoparticles that was supported over LDH structures. At the critical conditions of the temperature and the pressure, the nanoparticles of cobalt ferrite acted as catalysts for driving and accelerating the decomposition reactions of methanol molecules producing large amount of gases inside the LDH structures and increasing the internal pressure among the nanolayers. To release all these gases from the rigid nanolayers of $\mathrm{LDH}$, holes and vacancies were formed during the transformation of Co-Fe LDH to cobalt ferrite through the dehydroxylation process of the nanolayers. At the same time, the internal pressure of these gases inside the nanolayered structures directed the hexagonal plates of LDH to produce nano-net morphology.

The magnetic behavior of the cobalt ferrite nano-nets and the cobalt ferrite-supported LDH were measured and compared with the nanoparticles through vibrating sample magnetometer technique. The magnetic parameters indicated that the prepared nano-nets have ferromagnetic behavior and high coercivity. However, the prepared nanoparticles revealed superparamagnetic state and low coercivity. These results concluded that the incorporation of nanoparticles with nanowires into nano-net structures has been found to be an efficient way to improve their magnetic properties and prevent their agglomerations. Finally, layered double hydroxides are an important source for constructing magnetic nanolayered structures and nano-nets.

Author Contributions: O.S. is the corresponding author and has participated for preparation and characterization of the materials. A.A. participated for analyzing the experimental results. S.A. has prepared the materials and participated for measuring the physical properties. K.B. measured the magnetic properties of the prepared materials.

Funding: This research was funded by the Deanship of Scientific Research in King Faisal University (Saudi Arabia), grant number 17122002 and The APC was funded by the same grant number 17122002.

Acknowledgments: The authors thank the Deanship of Scientific Research in King Faisal University (Saudi Arabia) for funding and providing the facilities required for this research as a part of the Research Grants Program (no. 17122002).

Conflicts of Interest: The authors declare no conflict of interest.

\section{References}

1. Tran, H.D.; Li, D.; Kaner, R.B. One-Dimensional Conducting Polymer Nanostructures: Bulk Synthesis and Applications. Adv. Mater. 2009, 21, 1487-1499. [CrossRef]

2. Wang, X.F.; Ding, B.; Yu, J.Y.; Si, Y.; Yang, S.B.; Sun, G. Electro-netting: Fabrication of two-dimensional nano-nets for highly sensitive trimethylamine sensing. Nanoscale 2011, 3, 911-915. [CrossRef] [PubMed]

3. Saber, O.; Aljaafari, A.; Osama, M.; Alabdulgader, H. Accelerating the photocatalytic degradation of green pollutants through new coating technique for carbon nanotubes with nanolayered structures and nanocomposites. Chem. Open 2018, 7, 833-841.

4. Saber, O.; Alomair, H.A.; Abu-Abdeen, M.; Aljaafari, A. Fast degradation of green pollutants through nanonets and nanofibers of the Al-doped zinc oxide. Acta Metall. Sin. Engl. 2018, 31, 533-546. [CrossRef] 
5. Cao, H.Q.; Zheng, H.; Liu, K.Y.; Fu, R.P. Single-Crystalline Semiconductor $\operatorname{In}(\mathrm{OH})_{3}$ Nanocubes with Bifunctions: Superhydrophobicity and Photocatalytic Activity. Cryst. Growth Des. 2010, 10, 597-601. [CrossRef]

6. Wang, M.R.; He, J.H.; Yu, J.Y.; Pan, N. Lattice Boltzmann modeling of the effective thermal conductivity for fibrous materials. Int. J. Therm. Sci. 2007, 46, 848-855. [CrossRef]

7. Kodama, T.; Kitayama, Y.; Tsuji, M.; Tamaura, Y. Characterization of Ultrafine $\mathrm{Ni}_{x} \mathrm{Fe}_{3-\mathrm{x}} \mathrm{O}_{4}$ Particles Synthesized by Co-Precipitation: Size Regulation and Magnetic Properties. J. Magn. Soc. Jpn. 1996, 20, 305-308. [CrossRef]

8. Giri, A.K.; Kirkpatric, E.M.; Moongkhmklang, P.; Majctich, S.A. Photomagnetism and structure in cobalt ferrite nanoparticles. Appl. Phys. Lett. 2002, 80, 2341-2343. [CrossRef]

9. Giri, A.K.; Pellerin, K.; Pongsaksawad, W.; Sorescu, M.; Majetich, S.A. Effect of light on the magnetic properties of cobalt ferrite nanoparticles. IEEE Trans. Magn. 2000, 36, 3029-3031. [CrossRef]

10. Chen, Y.; Ruan, M.; Jiang, Y.F.; Cheng, S.G.; Li, W. The Synthesis and Thermal Effect of $\mathrm{CoFe}_{2} \mathrm{O}_{4}$ Nanoparticles. J. Alloys Compd. 2010, 493, L36-L38. [CrossRef]

11. Morais, P.C.; Garg, V.K.; Oliveira, A.C.; Silva, L.P.; Azevedo, R.B.; Silva, A.M.L.; Lima, E.C.D. Synthesis and characterization of size-controlled cobalt-ferrite-based ionic ferrofluids. J. Magn. Magn. Mater. 2001, 225, 37-40. [CrossRef]

12. Pillai, V.; Shah, D.O. Synthesis of High-Coercivity Cobalt Perrite Particles Using Water-in-Oil Microemulsions. J. Magn. Magn. Mater. 1996, 163, 243-248. [CrossRef]

13. Saber, O.; Mohamed, N.H.; Aljaafari, A. Synthesis of Magnetic Nanoparticles and Nanosheets for Oil Spill Removal. Nanosci. Nanotechnol. Asia 2015, 5, 32-43. [CrossRef]

14. Wu, M.; Xiong, Y.; Peng, Z.; Jang, N.; Qi, H.; Chen, Q. The enhanced coercivity for the magnetite/silica nanocomposite at room temperature. Mater. Res. Bull. 2004, 39, 1875-1880. [CrossRef]

15. Wanger, J.; Authenrieth, T.; Hempelmann, R. Core shell particles consisting of cobalt ferrite and silica as model ferrofluids $\left[\mathrm{CoFe}_{2} \mathrm{O}_{4}-\mathrm{SiO}_{2}\right.$ core shell particles. J. Magn. Magn. Mater. 2002, 252, 4-6.

16. Huang, X.H.; Chen, Z.H. Sol-gel preparation and characterization of $\mathrm{CoFe}_{2} \mathrm{O}_{4}-\mathrm{SiO}_{2}$ nanocomposites. Solid State Commun. 2004, 132, 845-850. [CrossRef]

17. Gharagozlou, M. Study on the influence of annealing temperature and ferrite content on the structural and magnetic properties of $\mathrm{x}\left(\mathrm{NiFe}_{2} \mathrm{O}_{4}\right) /(100-\mathrm{x}) \mathrm{SiO}_{2}$. J. Alloys Compd. 2010, 495, 217-223. [CrossRef]

18. Wang, L.; Li, J.; Lu, M.; Dong, H.; Hua, J.; Xu, S.C.; Li, H.B. Magnetic and Mössbauer spectroscopy studies of $\mathrm{NiFe}_{2} \mathrm{O}_{4} / \mathrm{SiO}_{2}$ nanocomposites synthesized by sol-gel method. J. Sol.-Gel Sci. Technol. 2015, 28, $191-196$. [CrossRef]

19. Nadeem, K.; Traussnig, T.; Letofsky-Papst, I.; Krenn, H.; Brossmann, U. Sol-gel synthesis and characterization of single-phase $\mathrm{Ni}$ ferrite nanoparticles dispersed in $\mathrm{SiO}_{2}$ matrix. J. Alloys Compd. 2010, 493, 385-390. [CrossRef]

20. Rohilla, S.; Kumar, S.; Aghamkar, P.; Sunder, S.; Agarwal, A. Investigations on structural and magnetic properties of cobalt ferrite/silica Nanocomposites prepared by the coprecipitation method. J. Magn. Magn. Mater. 2011, 323, 897-902. [CrossRef]

21. Wanga, X.; Dinga, B.; Yuc, J.; Yange, J. Large-scale fabrication of two-dimensional spider-web-like gelatin nano-nets via electro-netting. Colloids Surf. B 2011, 86, 345-352. [CrossRef] [PubMed]

22. Pant, H.R.; Pant, B.; Pokharel, P.; Kim, H.J.; Tijing, L.D.; Park, C.H.; Lee, D.S.; Kim, H.Y.; Kim, C.S. PhotocatalyticTiO $2-\mathrm{RGO} /$ nylon-6 spider-wave-like nano-nets via electrospinning and hydrothermal treatment. J. Membr. Sci. 2013, 429, 225-234. [CrossRef]

23. Hyde, S.T.; Friedrichs, O.D. From untangled graphs and nets to tangled materials. Solid State Sci. 2011, 13, 676-683. [CrossRef]

24. Saber, O. Improvement of optical properties and thermal stability of poly vinyl alcohol using salicylic acid confined in nanohybrid material. Polym. Bull. 2012, 68, 209-222. [CrossRef]

25. Meng, W.Q.; Li, F.; Evans, D.G.; Duan, X. Preparation of magnetic material containing $\mathrm{MgFe}_{2} \mathrm{O}_{4}$ spinel ferrite from a $\mathrm{Mg}-\mathrm{Fe}(\mathrm{III})$ layered double hydroxide intercalated by hexacyanoferrate (III) ions. Mater. Chem. Phys. 2004, 86, 1-4. [CrossRef]

26. Zhang, X.; Wang, D.; Zhang, S.; Maa, Y.; Yang, W.; Wang, Y.; Awaji, S.; Watanabe, K. Effect of high magnetic field annealing on the microstructure and magnetic properties of Co-Fe layered double hydroxide. J. Magn. Magn. Mater. 2010, 322, 3023-3027. [CrossRef] 
27. Chen, W.Q.; Wang, J.; Ma, K.Y.; Li, M.; Guo, S.H.; Liu, F.; Cheng, J.P. Hierarchical NiCo $\mathrm{O}_{4} @ \mathrm{Co}-\mathrm{Fe}$ LDH core-shell nanowire arrays for high-performance supercapacitor. Appl. Surf. Sci. 2018, 451, $280-288$. [CrossRef]

28. Saber, O.; El-Brolossy, T.; AlJaafari, A. Improvement of photocatalytic degradation of naphthol green B under solar light using aluminum doping of zinc oxide nanoparticles. Water Air Soil Pollut. 2012, 223, 4615-4626. [CrossRef]

29. Saber, O. Preparation and characterization of a new layered double hydroxide, Co-Zr-Si. J. Colloid Interface Sci. 2006, 297, 182-189. [CrossRef] [PubMed]

30. Mozaffarin, M.; Amighian, J.; Darsheshdar, E. Magnetic and structural studies of nickel-substituted cobalt ferrite nanoparticles, synthesized by the sol-gel method. J. Magn. Magn. Mater. 2014, 350, 19-22. [CrossRef]

31. Velinov, N.; Koleva, K.; Tsonchev, T.; Paneva, D.; Manova, E.; Tenchev, K.; Kunev, B.; Genova, I.; Mitov, I. Copper-cobalt ferrites as catalysts for methanol decomposition. Cent. Eur. J. Chem. 2014, 12, 250-259. [CrossRef]

32. Porter, J.R.; De Jonghe, L.C.; De Jonghe. Hydrogen reduction of cobalt ferrite. Metall. Trans. B 1981, 12, 299-309. [CrossRef]

33. Nejati, K.; Davaran, S.; Baggalzadeh, R. Synthesis and investigation of magnetic nanocomposite of Fe3O4 with cetirizine-intercalated layered double hydroxide. Superlattices Microstruct. 2014, 75, 257-267. [CrossRef]

34. Nadeem, K.; Zeb, F.; Azeem Abid, M.; Mumataz, M.; Rehman, A.M. Effect of amorphous silica matrix on structural, magnetic, and dielectric properties of cobalt ferrite/silica nanocomposites. J. Non-Cryst. Solids 2014, 400, 45-50. [CrossRef]

35. Gozuak, F.; Koseoglu, Y.; Baykal, A.; Kavas, H. Synthesis and characterization of $\mathrm{Co}_{\mathrm{x}} \mathrm{Zn}_{1-\mathrm{x}} \mathrm{Fe}_{2} \mathrm{O}_{4}$ magnetic nanoparticles via a PEG-assisted route. J. Magn. Magn. Mater. 2009, 321, 2170-2217. [CrossRef]

36. Saber, O. New trend for synthesizing of magnetic nanorods with titanomaghemite structure. J. Magn. Magn. Mater. 2016, 410, 10-17. [CrossRef]

37. Herrera, A.P.; Polo-Corrales, L.; Chavez, E.; Cabarcas-Bolivar, J.; Uwakweh, O.N.C.; Rinaldi, C. Influence of aging time of oleate precursor on the magnetic relaxation of cobalt ferrite nanoparticles synthesized by the thermal decomposition method. J. Magn. Magn. Mater. 2013, 328, 41-52. [CrossRef]

38. Chinnasamy, C.N.; Jeyadevan, B.; Shinoda, K.; Tohji, K.; Djayaprawira, D.J.; Takahashi, M.; Joseyphus, R.J.; Narayanasamy, A. Unusually high coercivity and critical single-domain size of nearly monodispersed $\mathrm{CoFe}_{2} \mathrm{O}_{4}$ nanoparticles. Appl. Phys. Lett. 2003, 83, 2862-2864. [CrossRef]

39. Cannas, C.; Musinu, A.; Ardu, A.; Orru, F.; Peddis, G.; Casu, M.; Sanna, R.; Angius, F.; Diaz, G.; Piccaluga, G. $\mathrm{CoFe}_{2} \mathrm{O}_{4}$ and $\mathrm{CoFe}_{2} \mathrm{O}_{4} / \mathrm{SiO}_{2}$ Core/Shell Nanoparticles: Magnetic and Spectroscopic Study. Chem. Mater. 2010, 22, 3353-3361. [CrossRef]

40. Girgis, E.; Adel, D.; Tharwat, C.; Attallah, O.; Rao, K.V. Cobalt ferrite nanotubes and porous nanorods for dye removal. Adv. Nano Res. 2015, 3, 111-121. [CrossRef] 